\title{
Blood Transfusion Guided by Physiological Markers
}

\author{
Mario A Rodríguez Domínguez ${ }^{1 *}$, Ana Maria Espinosa-Galindo ${ }^{1}$, Luis Javier Marfil-Rivera ${ }^{2}$ and Dionisio Palacios-Ríos ${ }^{1}$ \\ ${ }^{1}$ Department of Anesthesiology, University Hospital “Dr. José Eleuterio González", U.A.N.L., Monterrey, Nuevo Leon, Mexico \\ ${ }^{2}$ Department of Hematology, University Hospital “Dr. José Eleuterio González", U.A.N.L., Monterrey, Nuevo Leon, Mexico
}

${ }^{*}$ Corresponding author: Mario A Rodriguez Dominguez MD, Department of Anesthesiology, University, Hospital “Dr. José Eleuterio González”, Universidad Autonoma de Nuevo Leon (U.A.N.L.), Ave. Francisco I. Madero and Ave. Gonzalitos s/n, Col. Mitras Centro, C.P. 64460, Monterrey, Nuevo León, Mexico; Tel: +5218112525210; E-mail: rodolfot59@hotmail.com

Received: November 22, 2019; Accepted: November 27, 2019; Published: November 29, 2019

\begin{abstract}
Introduction: For decades, intraoperative anemia has been treated with red blood cell transfusions since it was believed that oxygen supply would increase by increasing hemoglobin levels. There is evidence that blood transfusion is associated with adverse events and should be avoid as much as possible. For this purpose, it is essential to know the compensatory physiological mechanisms during anemia. Venous oxygen saturation is a clinical tool that integrates the relationship between oxygen intake and consumption, which is easy to obtain once a central venous catheter, is available.
\end{abstract}

Material and methods: A longitudinal, prospective, observational study was conducted which included patients schedule for elective or emergency procedures that, due to their clinical conditions, had a central venous catheter. A sample of venous blood was taken from the central venous catheter and sent to the laboratory for gasometry. The results were correlated with the clinical status and vital signs of the patient. The following variables were evaluated: vital signs, hemoglobin, and hematocrit and oxygen saturation before and after transfusion.

Results: 34 patients were evaluated with an average age of 52 years. $58.8 \%$ was transfused. Despite the transfusion and variations of hemoglobin, the $\mathrm{SaO} 2$ in the pulse oximeter remained without changes pre and post transfusion. In gasometry, a difference between hemoglobin and initial hematocrit and pre-transfusion was observed, this due to bleeding that occurred. No differences in $\mathrm{SaO} 2$ values were observed for pre-transfusion vs posttransfusion pulse oximetry.

Conclusions: We found no evidence to support the linear correlation of ScvO2 with the hemoglobin levels, there is great variability of ScvO2 at different hemoglobin level, we suggest the use of venous central saturation as a physiological marker for transfusions, avoiding with this practice making decisions only with the hemoglobin levels.

Keywords: Transfusion, Oxygenation, Saturation, Blood, Hemoglobin, Catheter

\section{Introduction}

For decades, intraoperative anemia has been treated with red blood cell transfusions based on the concept that the oxygen supply to the tissues is increased by increasing hemoglobin levels. Likewise, arbitrary transfusion rules such as the "10/30 rule" have been used indicating that the transfusion of erythrocyte concentrates is required when the hemoglobin concentration is less than $10 \mathrm{~g} / \mathrm{dl}$ or the hematocrit decreases by $30 \%$ [1]. There is evidence that blood transfusion is associated with adverse events, so it should be avoided as much as possible [1-3]. For this purpose, it is essential to know the compensatory physiological mechanisms during anemia. The main function of red blood cells is the transport of oxygen from the pulmonary capillaries to the peripherals. The oxygen delivery (DO2) is defined as the product of cardiac output (CO) and arterial oxygen concentration $(\mathrm{CaO} 2) . \mathrm{DO} 2=\mathrm{CO} \times \mathrm{CaO} 2$ where $\mathrm{DO} 2$ is expressed in $\mathrm{mL} / \mathrm{min}, \mathrm{CO}$ in $\mathrm{dL} / \mathrm{min}$, and $\mathrm{CaO} 2$ in $\mathrm{mL} / \mathrm{dL}$.

The arterial oxygen concentration can be defined with the following formula: $\mathrm{CaO} 2=(\mathrm{SaO} 2 \times 1.34 \times \mathrm{Hb})+(0.0031 \times \mathrm{PaO} 2)$

Where $\mathrm{SaO} 2$ is the arterial saturation (in \%), 1.34 is the amount of oxygen carried on the hemoglobin (in $\mathrm{mL} / \mathrm{g}$ ), $\mathrm{Hb}$ represents the hemoglobin level (in $\mathrm{g} / \mathrm{dL}$ ), 0.0031 is the solubility coefficient of oxygen in human plasma at $37^{\circ} \mathrm{C}$ (in $\mathrm{mL} / \mathrm{dL}^{\star} \mathrm{mmHg}$ ) and $\mathrm{PaO} 2$ the arterial tension measure in $\mathrm{mmHg}$. From this equation, we can infer that to maintain the tissue oxygen supply the organism must adjust some variables such as: $\mathrm{Hb}, \mathrm{CO}$, oxygen consumption (VO2) and $\mathrm{SaO} 2$. The ratio of oxygen consumption (VO2) to oxygen delivery (DO2) is defined as "Oxygen extraction ratio" (O2ER) in normal circumstances the normal range is from $20-30 \%$ because the DO2 (800- $1200 \mathrm{~mL} / \mathrm{min})$ exceeds VO2 $(200-300 \mathrm{~mL} / \mathrm{min})$ three to five times. In this way the hemoglobin concentration and the oxygen delivery (DO2) can decrease significantly without affecting the oxygen consumption, which makes it independent of DO2 [4,5].

However, below a critical threshold of hemoglobin concentration (HbCRIT) and critical oxygen delivery (DO2 CRIT), a level of VO2 / DO2 dependence is reached. This means that below this threshold any decrease in $\mathrm{DO} 2$ or $\mathrm{Hb}$ also results in a decrease in $\mathrm{VO} 2$ and therefore in tissue hypoxia. Venous oxygen saturation is a clinical tool that integrates the relationship between the intake and oxygen consumption in the body, in absence of a mixed venous saturation sample ( $\mathrm{SvO} 2)$ obtained through a pulmonary arterial catheter, central venous oxygen saturation $(\mathrm{SvcO} 2)$ is being used as an accurate 
substitute. Central venous catheters are simpler to insert, safer and cheaper than pulmonary artery catheters [6].

By means of a central venous catheter, it is possible to take blood samples for the measurement of $\mathrm{ScvO} 2$, whose value ranges around $73 \%-82 \%[6,7]$. Since, as stated, the Hb level does not guarantee an adequate tissue perfusion. Accordingly, the physiological transfusion markers should replace the arbitrary markers currently used based only on hemoglobin levels $[8,9]$. In this way, we could avoid the unnecessary use of transfusions with the consequent savings in blood banks, reserving it only to those patients who really require it, avoid adverse transfusion reactions such as acute lung injury, infection transmission, among others. Transfusion guidelines should consider the individual ability of each patient to tolerate and compensate the acute decrement of hemoglobin concentration in the account that there is not a universal threshold to indicate a transfusion [10]. The markers should instead consider signs of tissue dysoxia, which may occur at different hemoglobin concentrations depending on the comorbidities of each patient. These signs may be based on signs and symptoms of inadequate oxygenation, however, before a decision is made regarding transfusion, it must be ensured that there is an adequate supply of volume with crystalloids and / or colloids and that the anesthetic management at the time is optimal. The objective of the present study was to demonstrate that physiological markers, specifically central venous saturation, are parameters that are useful to determine the use of blood transfusion

\section{Materials and Methods}

\section{Study design and ethical aspects}

A longitudinal, prospective, observational study was conducted which included patients from 18 to 60 years, of indistinct gender, who entered the operating room for any surgical procedure of any specialty in in a third level hospital. The procedures included needed to carry a risk of bleeding greater than $15-20 \%$ of the circulating blood volume and the patients that, due to its clinical conditions, required a central venous catheter. Exclusion criteria included patients who refuse to participate in the study, with active bleeding from the gastrointestinal tract, with anemia or blood dysrcrasias and hemodynamically unstable. The elimination criteria included patients in whom the history of blood dyscrasias is unknown or confirmed, patients who have some other pathological condition that alters the results and interpretation of the study, patients with active bleeding and who require an urgent blood transfusion. This protocol was submitted for evaluation to the ethics committee. Because the study was carried out only in patients who already have a central venous catheter in place, patient authorization was not required by informed consent. In the same way the patient was not intervened, since this is an observational study, only the data was collected and analyzed.

\section{Study variables}

For each patient who met the criteria a sample of venous blood was taken from the central venous catheter. The sample was then taken to the hospital's gasometry laboratory where the study was conducted. Once the result of the sample was obtained, it was captured in a database including as variables the results of arterial gasometries, vital signs and laboratory tests that the patient will have, such as blood count and blood chemistry.

\section{Statistical analysis}

Epidemiological data such as age and sex will be obtained. The data will be analyzed with measures of central tendency such as mean, median and dispersion measures such as the standard deviation. In the bivariate analysis, it is planned to use the Shapiro-Wilk test to observe the dispersion of the data and classify it as parametric or non-parametric. Based on the results obtained, non-parametric statistical tests such as square chi for two groups and Wilcoxon were performed, given that related groups are compared. If the results obtained are parametric, tests such as Student's T will be performed for related groups. The SPSS version 24 program was used to perform the statistical tests described above.

\section{Results}

34 patients were evaluated with an age average of 76 years ( \pm 16 years). The average weight of the patients was $80 \mathrm{~kg}$ and the average size was $164 \mathrm{~cm} .64 .7 \%$ of the patients were male and $35.3 \%$ female (Table 1). $58.8 \%$ of the patients evaluated had the need to be transfused. An average of $777 \mathrm{~cm} 3$ of blood was transfused; the most common amount of transfused packets was two globular packages. Vital signs were evaluated with a range of $83-84$ beats per minute, respiratory frequency varied from 21 breaths per minute prior the surgical procedure and an average pulse oximeter saturation of $98 \%$. Systolic blood pressure fluctuated from $127-109 \mathrm{mmHg}$ at the end of the procedure and the initial diastolic pressure was $74-\mathrm{mmHg}$ compare to the $66 \mathrm{mmHg}$ at the end of the procedure. (Figure 1-4). An initial mean $\mathrm{Hb}$ was obtained in venous gases of 8.9, pretransfusion of 7.8 and post transfusion of 10 . A statistically significant difference was observed in pre and post transfusion hemoglobin, as well as in pre and post transfusion hematocrit unlike $\mathrm{SaO} 2$, where there was no difference between pre-transfusion and post transfusion. In arterial gases, a statistically significant difference was found in the initial hematocrit levels and the hemoglobin levels pre transfusion, no differences were observed in $\mathrm{SaO} 2$ values or in any of the pretransfusion vs. post-transfusion data (Table 2). Finally, a comparative analysis between the markets as cut- off points in the literature reviewed was made. A chi-square cross-tabulation table analysis was performed for qualitative variables, where no statistically significant differences were found in patients with indication of transfusion at the beginning of the procedure; pre-intervention and post-intervention (Table 3).

Table 1. Demographic characteristics of the patients.

\begin{tabular}{|l|l|}
\hline \multicolumn{2}{|l|}{ Demographic data } \\
\hline Patients & 34 \\
\hline Age (years) & 52 \\
\hline Size (cm) & $164 \pm 11$ \\
\hline Weight $(\mathrm{kg})$ & $80 \pm 20$ \\
\hline Gender & $22(64.7)$ \\
\hline Female 11 (\%) & $12(35.3)$ \\
\hline Male 11 (\%)
\end{tabular}


Table 2. Venous and arterial gases, pre transfusion and post transfusion.

\begin{tabular}{|c|c|c|c|c|c|c|}
\hline & Initial & Pre transfusion & $\mathbf{P}$ & Pre transfusion & Post transfusion & $\mathbf{P}$ \\
\hline \multicolumn{7}{|c|}{ Venous Gases } \\
\hline $\mathrm{Hb}$ & 8.980 & 7.800 & 0.074 & 7.800 & 10.028 & 0.008 \\
\hline Hcto & 29.500 & 24.631 & 0.031 & 24.631 & 32.011 & 0.008 \\
\hline $\mathrm{SaO} 2$ & 118.35 & 72.94 & 0.198 & 72.94 & 114.50 & 0.683 \\
\hline \multicolumn{7}{|c|}{$\begin{array}{l}\text { Arterial } \\
\text { Gases }\end{array}$} \\
\hline $\mathrm{Hb}$ & 9.970 & 8.893 & 0.035 & 8.93 & 9.817 & 0.239 \\
\hline Heto & 31.65 & 28.53 & 0.035 & 28.53 & 31.67 & 0.195 \\
\hline $\mathrm{SaO} 2$ & 99.00 & 98.73 & 0.627 & 98.73 & 98.83 & 0.219 \\
\hline
\end{tabular}

Table 3. Patients with indication of transfusion at the beginning of the procedure, pre intervention and post intervention.

\begin{tabular}{|c|c|c|c|c|c|c|}
\hline & $\begin{array}{c}\text { Venous } \\
\text { Hb }\end{array}$ & $\begin{array}{c}\text { Venous } \\
\mathrm{SaO2}\end{array}$ & $\mathbf{P}$ & $\begin{array}{c}\text { Arterial } \\
\mathrm{Hb}\end{array}$ & $\begin{array}{c}\text { Arterial } \\
\mathrm{SaO2}\end{array}$ & $\mathbf{P}$ \\
\hline \multicolumn{7}{|l|}{ Initials } \\
\hline Requires transfusion & 17 & 6 & 0.05 & 19 & 0 & $*$ \\
\hline No transfusion required & 15 & 32 & & 14 & 32 & * \\
\hline \multicolumn{7}{|l|}{ Pre intervention } \\
\hline Requires transfusion & 17 & 6 & 0.554 & 15 & 19 & $*$ \\
\hline No transfusion required & 2 & 13 & & 4 & 15 & \\
\hline \multicolumn{7}{|l|}{ Post intervention } \\
\hline Requires transfusion & 12 & 9 & 0.056 & 13 & 21 & 0.05 \\
\hline No transfusion required & 10 & 12 & & 8 & 13 & \\
\hline
\end{tabular}

* The variables evaluated are constant, so there is no statistically significant difference.

\section{Heart Rate}

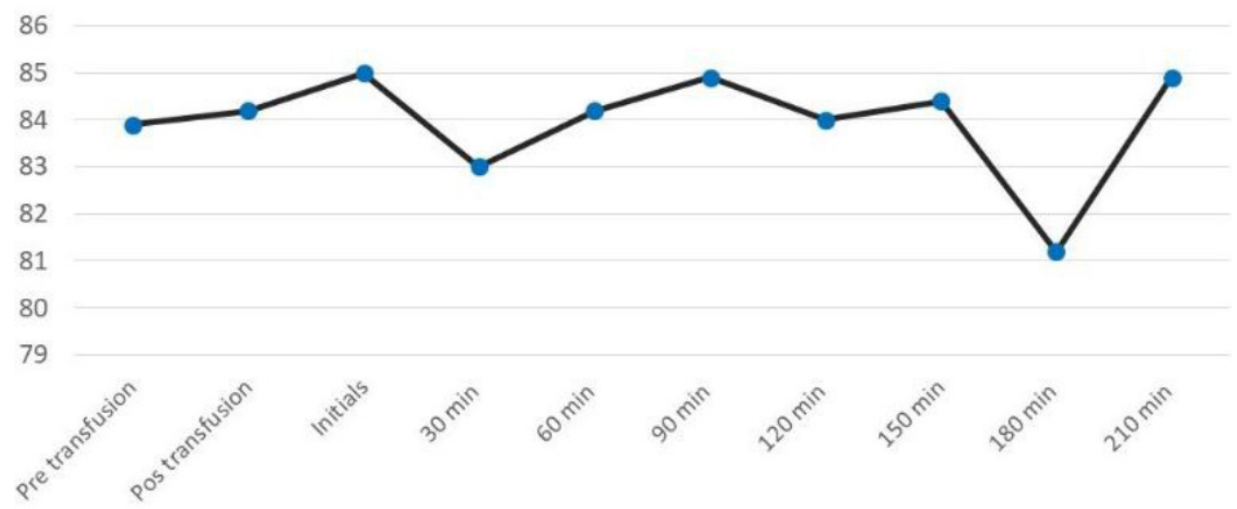

Figure 1. Average Hear Rate. 


\section{Breathing Rate}

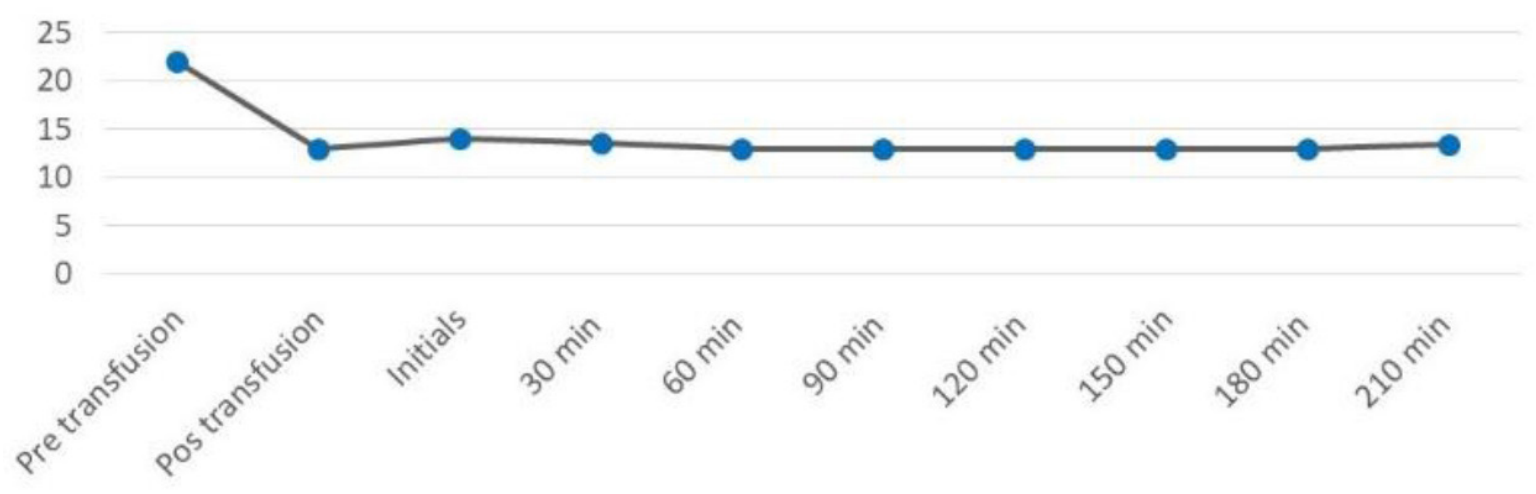

Figure 2. Average Breathing Rate.

\section{Systolic Pressure}

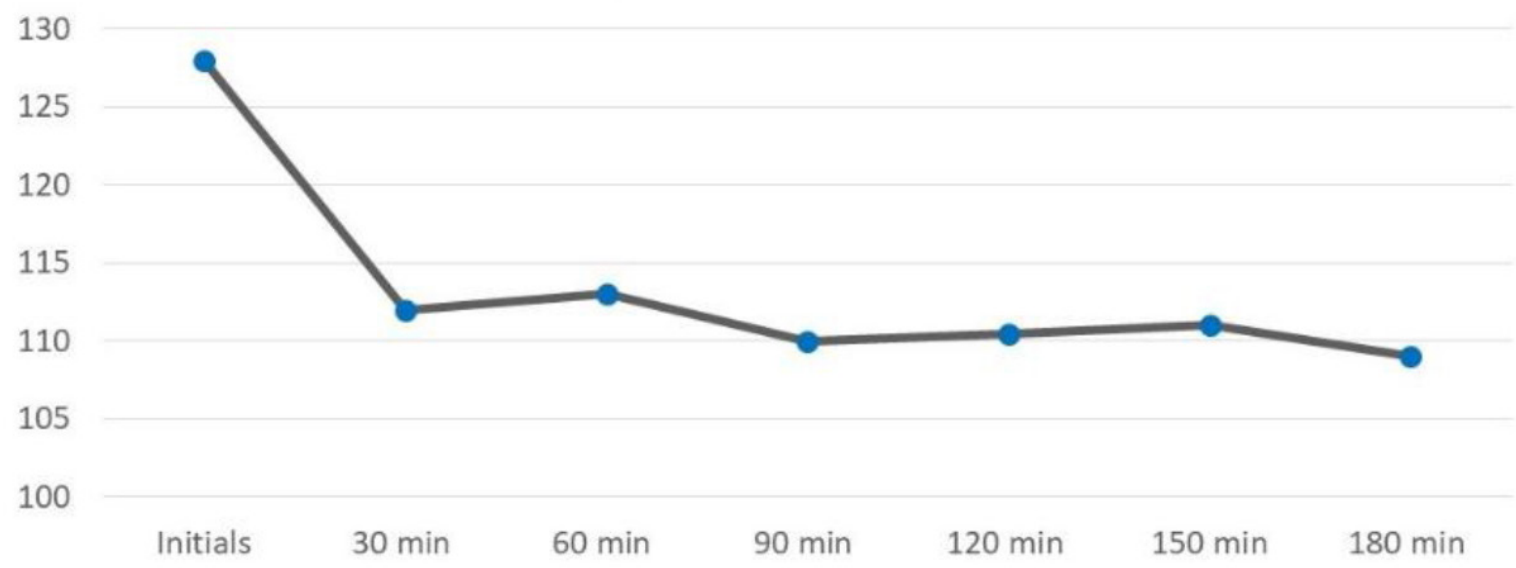

Figure 3. Average Systolic Pressure.

\section{Diastolic Pressure}

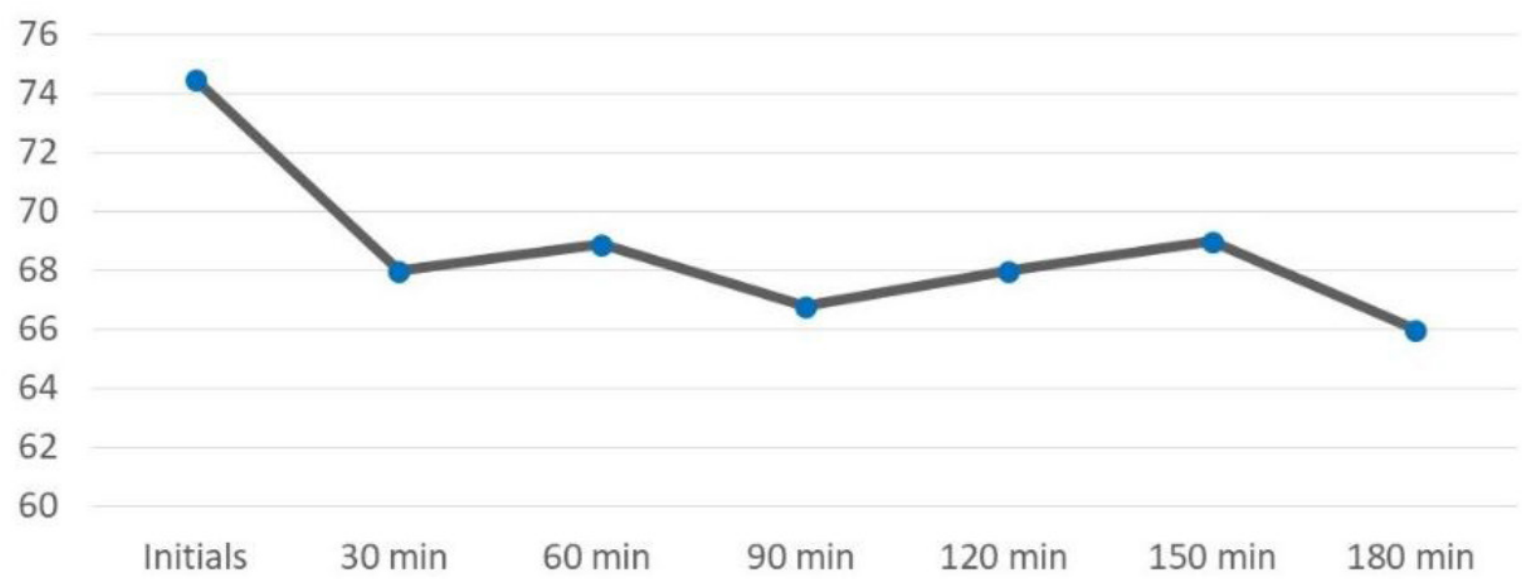

Figure 4. Average Diastolic Pressure. 


\section{$\mathrm{SaO2}$}

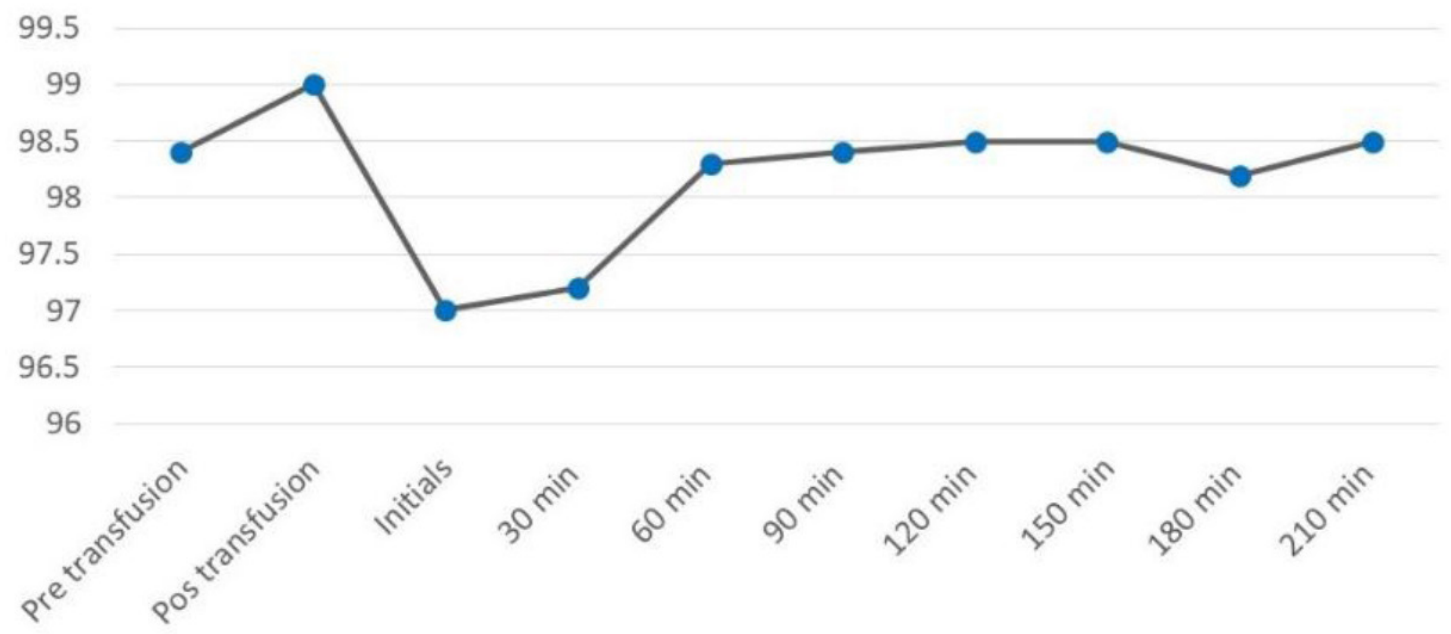

Figure 5. Average Arterial Oxygen Saturation.

\section{Discussion}

Based on the considerations above, the present investigation was carried out, with the aim of demonstrating, within our institution and in the operating room environment, the need to take other considerations in addition to a laboratory value when indicating a transfusion. The transfusion of erythrocyte concentrates is a very common practice within the operating room, it is very important for those who are responsible for carrying out this work to have deep knowledge about the physiology and biochemistry involved in the oxygenation process. This in order to achieve the main objective of hemotransfusion, without neglecting the other two variables that the blood influences, which are the rheological and volume effect $[11,12]$.

Unfortunately, routinely monitored variables such as blood pressure, heart rate, urine output, arterial gases and filling pressures do not necessarily reflect tissue perfusion. The mixed venous saturation $(\mathrm{SvO} 2)$ and central venous oxygen saturation $(\mathrm{SvcO} 2)$ are better indicators of oxygen delivery (DO2) and perfusion [13, 14]. The hemoglobin value has been considered as the determinant to indicate blood transfusion for many years. Although there are guides from different associations and different countries that provide us with great support when deciding if it is necessary to administer blood components to our patients, we propose that we also seek the support of physiological variables and markers when making this important decision. Taking into consideration that nowadays, at an international level, the transfusion of blood components cannot yet be performed without a residual risk $[15,16]$.

The appropriate use of blood components should be promoted, avoiding abuse, by developing medical guidelines for therapeutic use by specialties based on scientific evidence. Awareness should be made of the high cost of production, the permanent existence of residual risks of infectious diseases and the possibility of causing immediate or late post-transfusion reactions in the patient [17]. Understanding the costs associated with blood products requires extensive knowledge about transfusion medicine and this is attracting not only clinicians but also administrative personnel from the health care sector worldwide. To improve both the clinical and the economic situation, the use of blood bank resources should be optimized [17-19]. Estimate the costs of storage, procurement, transfer among others is complex, however they should be minimized and used only when strictly necessary based on clinical judgment and on the use of technology and tools that allow estimating the state of patient oxygenation. With a rapid and accessible examination in many of the hospitals where surgical procedures are performed, we can obtain data about tissue oxygenation and thus be able to decide more effectively the use of blood bank resources.

\section{Conclusion}

This study does not find enough evidence to support the correlation of $\mathrm{ScVO} 2$ with hemoglobin, that is, there is great variability in venous saturation at different hemoglobin levels, and however, there is a tendency to increase $\mathrm{ScvO} 2$ after transfusion of globular packages. In the absent of a mixed venous saturation sample ( $\mathrm{SvO} 2)$ which is obtain via a Swan Ganz catheter, the central venous oxygen saturation $(\mathrm{SvcO} 2)$ is a precise substitute and a reliable tool that integrates the relationship between the supply and consumption of oxygen in the body. By means of a central venous catheter, it is possible to take blood samples for the measurement of ScvO. We recommend that in patients who have this catheter use it to obtain a sample for gasometry and guide better decision-making regarding blood administration. There is an increase in interest in the use of mixed venous saturation and central venous saturation to guide therapeutic interventions during the intraoperative period. However, an understanding of the physiological principles and venous oximetry are essential for safe use in clinical practice. The venous oxygen saturation reflects the balance between the overall oxygen supply and its consumption, which can be affected by a large number of factors during the intraoperative period. 


\section{References}

1. Madjdpour C, Spahn DR, Weiskopf RB (2006) Anemia and perioperative red blood cell transfusion: a matter of tolerance. Crit Care Med 34: S102-108. [crossref]

2. Vazquez Flores JA (2006) La seguridad de las reservas sanguíneas en la república mexicana. Revista de Investigación Clínica 58: 101-108.

3. Añón JM, García de Lorenzo A, Quintana M, González E, Bruscas MJ (2010) [Transfusion-related acute lung injury]. Med Intensiva 34: 139-149. [crossref]

4. Walley KR (2011) Use of central venous oxygen saturation to guide therapy. Am J Resp Crit Care 184(5): 514-520.

5. Cain SM (1965) Appearance of excess lactate in anesthetized dogs during anemic and hypoxic hypoxia. Am J Physiol 209: 604-610. [crossref]

6. Vallet B, Emmanuel Robin, Lebuffe G (2010) Venous oxygen saturation as a physiologic transfusion trigger. Critical Care 14: 213.

7. Reinhart K, Kuhn HJ, Hartog C, Bredle DL (2004) Continuous central venous and pulmonary artery oxygen saturation monitoring in the critically ill. Intens Care Med 30: $1572-1578$.

8. Adamczyk S, Robin E, Barreau O, Fleyfel M, Tavernier B, et al. (2009) Contribution of central venous oxygen saturation in postoperative blood transfusion decision. Ann Fr Anesth 28: 522-530.

9. Vincent JL (2012) Transfusion triggers: getting it right! Crit Care Med 40: 3308 3309. [crossref]

10. Vallet B, Adamczyk S, Lebuffe G (2007) Physiologic transfusion triggers. Best Pract Res Clin Anaesthesiol. 21: 173-181.

11. Colomina M, Guilabert P (2016) Transfusion according to haemoglobin levels or therapeutic objectives. Rev Esp Anestesiol Reanim 63: 65-68.

12. Shander A, Gross I, Hill S, Javidroozi M, Sledge S (2013) A new perspective on best transfusion practices. Blood Transfus 11: 193-202.

13. Carrillo R, Núñez J (2007) Saturación venosa central. Conceptos actuales. Rev Mex Anestesiol 30: 165-171.

14. Cabrales P, Intaglietta M, Tsai AG (2007) Transfusion restores blood viscosity and reinstates microvascular conditions from hemorrhagic shock independent of oxygen carrying capacity. Resuscitation 75: 124-134. [crossref]

15. Shander A, Hofmann A, Gombotz H, Theusinger OM, Spahn DR (2007) Estimating the cost of blood: past, present, and future directions. Best Pract Res Clin Anaesthesiol 21: 271-289. [crossref]

16. Rojo J (2014) Enfermedades infecciosas transmitidas por transfusión. Panorama internacional y en México. Gac Med Mex 150: 78-83

17. Goodnough LT (2005) Risks of blood transfusion. Anesthesiol Clin North Am 23: 241-252, [crossref].

18. Shepherd SJ1, Pearse RM (2009) Role of central and mixed venous oxygen saturation measurement in perioperative care. Anesthesiology 111: 649-656. [crossref]

19. Park D, Chun B, Kwon S (2012) Red blood cell transfusions are associated with lower mortality in patients with severe sepsis and septic shock: A propensitymatched analysis. Crit Care Med 40: 3140-3145.

\section{Citation:}

Rodríguez Domínguez AM, Espinosa-Galindo AM, Marfil-Rivera LJ, Palacios-Ríos D (2019) Blood Transfusion Guided by Physiological Markers. Internal Med Res Open $J$ Volume 4 (2): 1-6. 